\title{
A naphthalene diimide G-quadruplex ligand inhibits cell growth and down-regulates BCL-2 expression in an imatinib-resistant gastrointestinal cancer cell line
}

Mekala Gunaratnam, Gavin W Collie ${ }^{a}$, Anthony P Reszka, Alan K Todd, Gary N Parkinson and Stephen Neidle*

UCL School of Pharmacy, University College London, 29-39 Brunswick Square, London WC1N IAX, UK

${ }^{a}$ Current address: Discovery Sciences, IMED Biotech Unit, AstraZeneca, Cambridge, UK *Corresponding author.

Tel +440207753 5969

Email s.neidle@ucl.ac.uk

Keywords:

Cancer, quadruplex nucleic acids, resistance 


\begin{abstract}
Gastro-intestinal tumours (GISTs) are driven by aberrant expression of the c-KIT oncoprotein. They can be effectively treated by the kinase inhibitor imatinib, which locks the c-KIT kinase domain into an inactive conformation. However resistance to imatinib, driven by active-site mutations, is a recurrent clinical challenge, which has been only partly met by the subsequent development of second and third-generation c-KIT inhibitors.

It is reported here that a tetra-substituted naphthalene diimide derivative, which is a micromolar inhibitor of cell growth in a wild-type patient-derived GIST cell line, has a submicromolar activity in two distinct patient-derived imatinib-resistant cell lines. The compound has been previously shown to down-regulate expression of the c-KIT protein in a wild-type GIST cell line. It does not affect c-KIT protein expression in a resistant cell line to the same extent, whereas it profoundly down-regulates the expression of the anti-apoptopic protein BCL-2. It is proposed that the mechanism of action involves targeting quadruplex nucleic acids, and in particular those in the $B C L-2$ gene and its RNA transcript. The BCL-2 protein is up-regulated in the GIST-resistant cell line, and is strongly down-regulated after treatment. The compound strongly stabilises a range of G-quadruplexes including a DNA one from the BCL-2 promoter and an RNA quadruplex from its 5'-UTR region. A reporter assay construct incorporating the 5'-UTR quadruplex sequence demonstrates down-regulation of $B C L-2$ expression.
\end{abstract}




\section{Introduction}

Gastrointestinal stromal tumours (GIST) are dependent in large part for tumour initiation and their continuing growth on the aberrant expression of the c-KIT growth factor receptor, which contains a tyrosine kinase domain. ${ }^{1-4}$ This kinase can be down-regulated by the $\mathrm{CML}$ (chronic myelogenous leukaemia) kinase inhibitor drug imatinib (Glivec ${ }^{\circledR}$ ), which maintains cKIT in an inactive state by binding to the ATP active site. Imatinib has received clinical approval for the treatment of GIST, where it has a major effect in terms of shrinking tumour size and thus resulting in increased patient life-span. ${ }^{5-7}$ However a proportion of GIST patients are inherently resistant to imatinib and for a substantial majority of others, mutations in the C-KIT active site, for example in exon 9, eventually result in the onset of secondary clinical resistance and tumour regrowth. ${ }^{4,8}$ A number of second-generation C-KIT inhibitors have been developed ${ }^{8}$, with the multi-targeted kinase inhibitors Sunitinib ${ }^{9,10}$ and more recently Regorafenib ${ }^{11,12}$ having received regulatory approval. However Sunitinib treatment frequently results in further secondary mutations. It is also ineffective against mutations in exon 17. Regorafenib is active in tumours that are resistant to both imatinib and Sunitinib, although it can cause severe liver toxicity in a substantial number of patients.

We have previously reported ${ }^{13}$ a distinctive approach to directly targeting the c-KIT gene which has exploited our earlier findings that the c-KIT promoter contains two putative quadruplex-forming sequences. ${ }^{14,15}$ These, c-KIT1 and c-KIT2, can form G-quadruplex higherorder structures, at least in vitro. ${ }^{16-20}$ Such intramolecular quadruplexes are formed from G-rich repeat nucleotide sequences folded into four-stranded structures, stabilized through Hoogsteen hydrogen bonding of G-quartet motifs together with potassium or sodium counterions coordinated between the quartets. ${ }^{21} \mathrm{~A}$ number of studies have now shown that the $c-K I T$ quadruplexes can be stabilised by appropriate small molecules, resulting in the inhibition of cKIT transcription. ${ }^{13,22-24}$ In particular we have used a tetra-substituted naphthalene diimide derivative $^{13,25}$ (Compound 1: Figure 1) for this purpose. This compound produces potent cell growth arrest in several c-KIT expressing cell lines, as well as in the patient-derived GIST cell line GIST882. ${ }^{13}$ By contrast, this cell line did not show sensitivity to the established quadruplexbinding compounds BRACO- $19^{26}$ and TMPyP4. ${ }^{27}$ We now report that compound 1 also potently 
inhibits growth in two imatinib-resistant patient-derived GIST cell lines, and we present evidence supportive of distinctive quadruplex-mediated mechanisms of action.

\section{Figure 1}

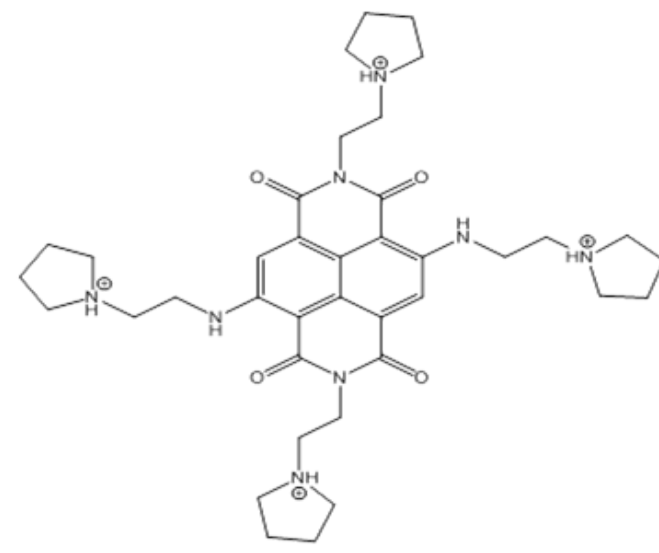

Over-expression of the BCL-2 protein has also been associated with worsening prognosis following imatinib treatment in GIST patients ${ }^{28}$ and the $\mathrm{BCL}-2$ inhibitor ABT-737 can induce apoptosis in GIST cell lines. ${ }^{29} \mathrm{BCL}-2$ (the B-cell lymphoma gene-2) encodes a $25 \mathrm{kDa}$ membrane protein that is involved in a complex system of signalling that controls apoptosis. The overexpression of $B C L-2$ prevents apoptosis and can contribute to metastasis in certain cancer types and is often associated with drug resistance. $\mathrm{BCL}-2$ protein expression down-regulation can be used to increase the effectiveness of anti-cancer drugs and has been validated as a therapeutic target. $^{30} B C L-2$ over-expression was first identified in follicular lymphomas linked to the chromosomal translocation $\mathrm{t}(14 ; 18)$ where the gene is positioned adjacent to the IG heavy chain locus on chromosome $14 .^{31}$

The human $B C L-2$ gene has been shown to contain a number of putative quadruplex forming sequences. Two in the promoter region, ${ }^{32-35}$ and one in a 5'-UTR region of the mRNA, ${ }^{36,37} 42$-nucleotides upstream of the translation start site, have been previously reported to form quadruplex arrangements, at least in vitro. A number of quadruplex-binding small molecules have been reported to bind to one or other of the $\mathrm{BCL}-2$ promoter quadruplexes and thereby down-regulate BCL-2 expression. ${ }^{38-42}$ To our knowledge, there are no reports to date of translational down regulation of BCL-2 via the BCL-2 5'-UTR RNA quadruplex. However a small number of other RNA quadruplexes have been successfully targeted, notably the 5'-UTR NRAS $^{43}$ and k-RAS ones, ${ }^{44}$ as well as an intronic RNA quadruplex transcribed by the C9orf 72 gene. $^{45}$

Our aim in this study has been to investigate the effects of the specific quadruplex stabilizing small molecule compound 1, on C-KIT and BCL-2 protein expression levels in both the wild-type 
GIST882 and an imatinib-resistant GIST cell line. The clinically-approved drugs for GIST are kinase inhibitors. An aim of this study then has been to examine whether drug resistance in GIST cells can be overcome at the gene rather than the protein level.

\section{Results}

The extent of quadruplex stabilisation by compound 1, BRACO-19 and imatinib was estimated using a high-throughput FRET (Fluorescence Resonance Energy Transfer) method, for a group of quadruplexes in $60 \mathrm{mM} \mathrm{KCl}$ or $\mathrm{NaCl}$-cacodylate solution.

Table 1. Changes in melting temperature $\left(\Delta \mathrm{T}_{\mathrm{m}}\right)$, in ${ }^{\circ} \mathrm{C}$, for five quadruplex-forming sequences and a representative duplex sequence, with $0.5 \mu \mathrm{M}$ of compound 1 , imatinib and the quadruplex ligand BRACO-19, obtained using a FRET procedure. All measurements were made in triplicate and the mean s.d. is $\pm 0.1^{\circ} \mathrm{C}$. Solutions were in $60 \mathrm{mM} \mathrm{KCl}$-cacodylate buffer, apart from those with the BCL-2 RNA quadruplex, which were in $60 \mathrm{mM} \mathrm{NaCl}$-cacodylate buffer.

\begin{tabular}{l|c|c|c|c|c|c|c|}
\hline & F21T & c-KIT1 & C-KIT2 & $\begin{array}{c}\text { Promoter } \\
\text { BCL-2 }\end{array}$ & $\begin{array}{c}\text { 5'-UTR } \\
\text { BCL-2 }\end{array}$ & Duplex \\
\cline { 3 - 8 } & Compound 1 & 29.7 & 11.2 & 29.0 & 27.6 & 10.7 & 3.5 \\
\cline { 3 - 8 } \\
he \\
FRET \\
resul \\
ts
\end{tabular}

(Table 1) show that imatinib does not significantly stabilise any of the quadruplexes or duplex 
DNA, whereas compound $\mathbf{1}$ in particular, is an outstandingly potent stabiliser of quadruplex structures, and superior to BRACO-19 for all the quadruplexes examined in this study. It is notable that compound $\mathbf{1}$ also appears at first sight to show selectivity for the promoter DNA quadruplex of the BCL-2 gene over the 5'-UTR RNA quadruplex. However the melting experiments have been performed in different ionic conditions, $60 \mathrm{mM}$ in $\mathrm{K}^{+}$for the DNA quadruplexes and $60 \mathrm{mM}$ in $\mathrm{Na}^{+}$for the RNA one, since the melting temperature for the highly stable RNA BCL-2 quadruplex is 91 ㅇ $\mathrm{C}$ in $60 \mathrm{mM} \mathrm{K}^{+}$solution, compared to $64.5 \circ \mathrm{C}$ in $60 \mathrm{mM} \mathrm{Na}^{+}$ solution, so a clear conclusion cannot be made on the basis of this data alone.

The cell growth inhibition studies (Table 2) show that imatinib is active in the non-resistant C-KIT cell line GIST882 and the two non-GIST tumour lines HT-29 and HCG-27, whereas it is less active in the MCF-7 breast carcinoma line and the two patient-derived imatinib-resistant lines GIST48 and GIST62. By contrast, compound 1, which is readily taken up into cells, is active across all lines, and in the two resistant lines results in an $\mathrm{IC}_{50}$ value of $<1.0 \mu \mathrm{M}$. BRACO-19 does not show significant activity in any of the GIST lines.

\begin{tabular}{|c|c|c|c|c|c|c|}
\hline & GIST882 & GIST48 & GIST62 & HT-29 & HGC-27 & MCF-7 \\
\hline Compound 1 & 1.6 & 0.5 & 0.4 & 0.04 & 0.1 & 0.01 \\
\hline Imatinib & 1.7 & 19.8 & $>25$ & 0.06 & 2.4 & 11.3 \\
\hline BRACO-19 & $>25$ & $>25$ & $>25$ & 2.7 & 2.3 & 2.2 \\
\hline
\end{tabular}

Table 2. Short-term $96 \mathrm{hr}$ anti-proliferative activity for the three compounds in a panel of six cancer cell lines, shown as $\mathrm{IC}_{50}$ values (in $\mu \mathrm{M}$ ). Standard deviations from $>3$ individual determinations are in the range $\pm 0.05-0.2 \mu \mathrm{M}$. 
The previous study on the mode of action of compound 1 in GIST882 cells indicated that two quadruplex-linked mechanisms were involved in (i) inhibition of telomerase action and (ii) down-regulation of c-KIT expression at the transcriptional level. Both of these have now been examined in the GIST48 imatinib-resistant cell line. Compound 1 does not show any significant effect on the ability of telomerase to add telomeric repeat units to the $3^{\prime}$ ends of telomeres in GIST48 (Figure 2a), at least at the concentrations used here. This is in contrast to its high potency against telomerase in the wild-type GIST882 cell line. The compound also shows a reduced effect on c-KIT protein expression levels (Figure $2 \mathrm{~b}$ ) with a $17 \%$ drop in protein levels after 24 hrs and $37 \%$ after one week compared to $\beta$-actin controls. By contrast, in the GIST882 cell line, at a

a)

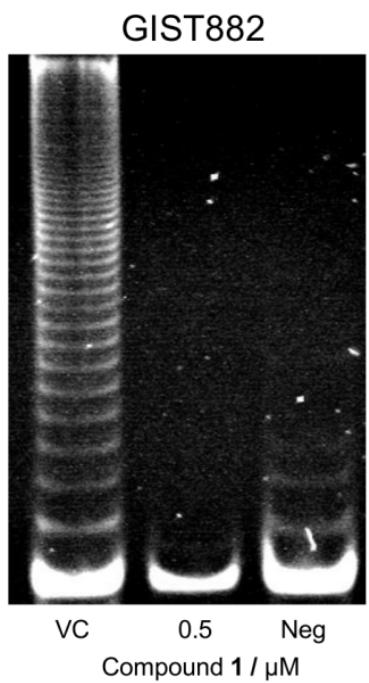

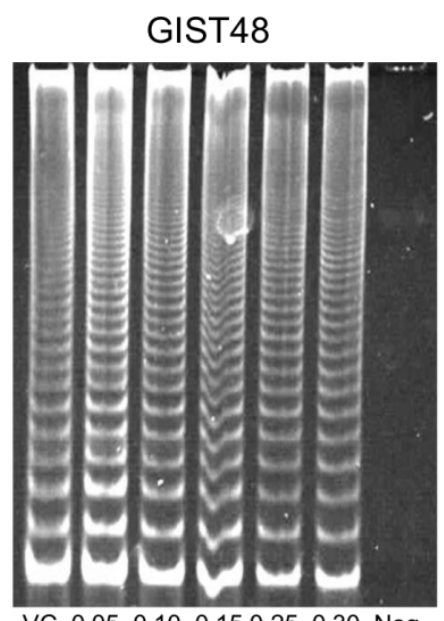

VC $\begin{array}{llllll}0.05 & 0.10 & 0.15 & 0.25 & 0.30 \mathrm{Neg}\end{array}$ Compound $1 / \mu \mathrm{M}$ b)
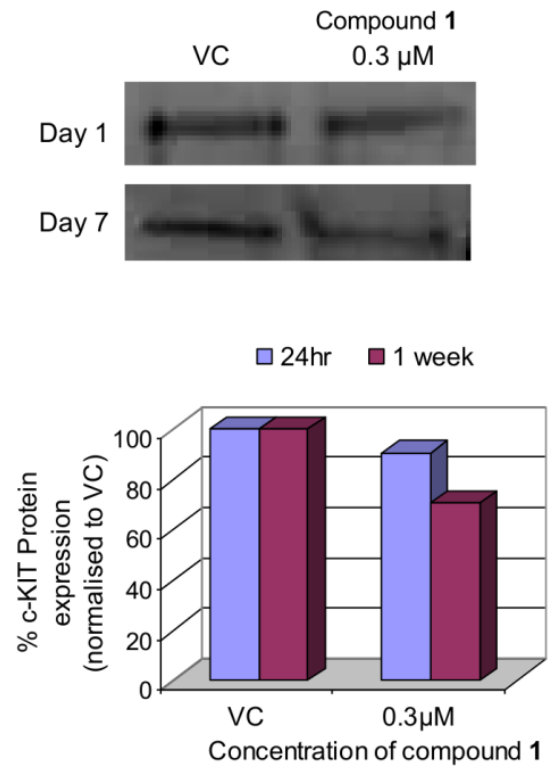

Figure 2 
sub-cytotoxic concentration of $1 \mu \mathrm{M}$, c-KIT protein expression was reduced by $90 \%$ in $24 \mathrm{hrs}$, relative to a GAPDH control. ${ }^{13}$ The expression levels of the anti-apoptopic protein BCL-2 have been compared in the GIST882 and GIST48 cell lines (Figure 3a), showing significant upregulation in the latter line and evidence of only low-level expression in GIST882. A timedependent study of the effects of a sub-cytotoxic concentration of compound $\mathbf{1}$ in the GIST48 line (Figures 3b, 3c), shows a ca $85 \%$ reduction in BCL-2 protein levels after one week of exposure, relative to $\beta$-actin controls.

a)

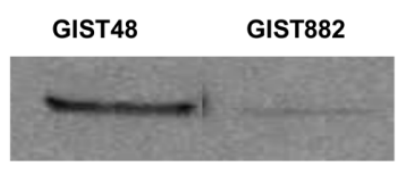

b)

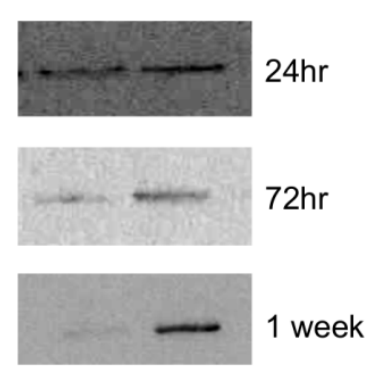

c)

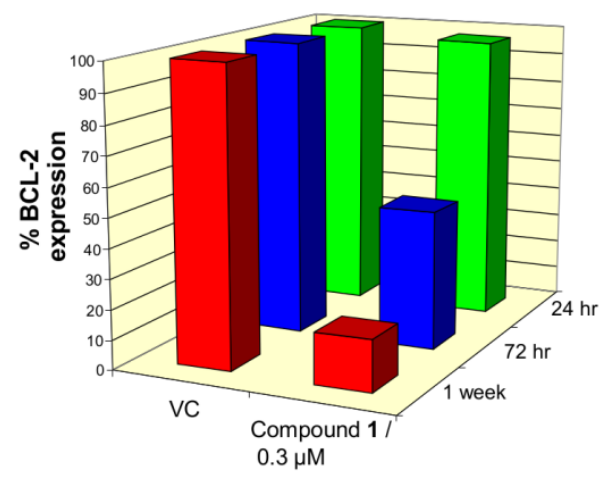

\section{Figure 3}

In view of the identification of a quadruplex-forming sequence in the 5'-UTR region of the BCL-2 mRNA, upstream of the translation start site, we have investigated the role that this site might play in regulating BCL-2 translation in the presence of compound 1. A dual luciferase reporter assay has been established in which the $67 n t$ sequence directly upstream of the BCL-2 translation start site has been inserted upstream of 
a)

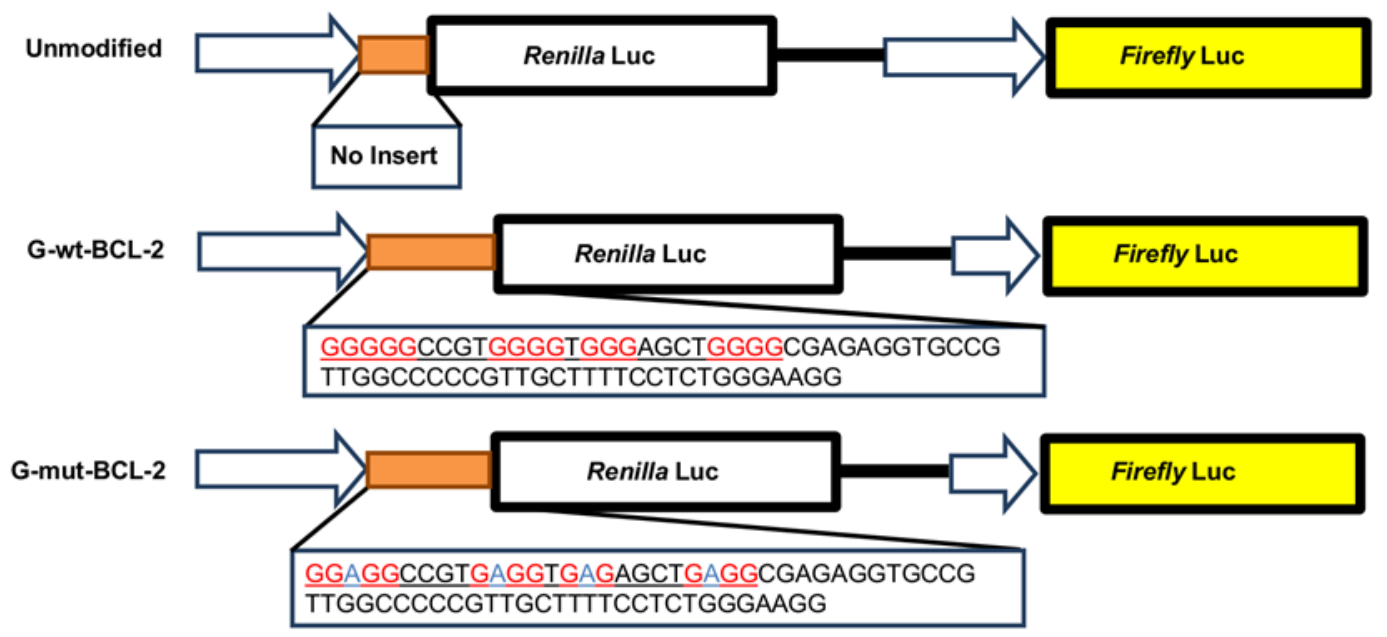

b)

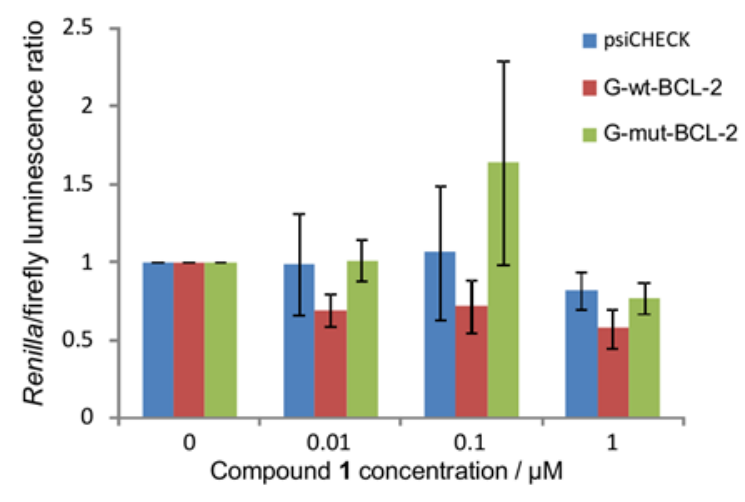

\section{Figure 4}

Renilla and firefly luciferase genes. A control reporter construct was also designed in which all G-rich tracts were modified with a single G-to-A substitution. The reporter assay constructs are shown in Figure 4a. The translation activities (as measured by the Renilla/firefly luminescence ratio) of these plasmids were initially assessed in vitro using a rabbit reticulocyte lysate system. These experiments showed that the insertion of the $67 \mathrm{nt}$ sequence from the BCL6 5' UTR (Gwt-BCL-2) significantly reduced protein expression (as measured by the Renilla/firefly luminescence ratio) compared to the mutated construct (G-mut-BCL-2) and the empty vector control (Figure S1). These findings are in line with previously reported results. ${ }^{36}$ The plasmids were then transfected into GIST882 cells and the Renilla and firefly luciferase luminescence activities were recorded as a measure of protein expression. Addition of compound $\mathbf{1}$ showed an approximately dose-dependent inhibition of expression response with the wild-type BCL-2 5'-UTR sequence G-wt-BCL-2 compared to the psiCHECK sequence (containing no insert) and 
the mutated BCL-2 5'-UTR plasmid G-mut-BCL-2 (Figure 4b), with a $30 \%$ reduction in translation at a ligand concentration of $10 \mu \mathrm{M}$, with no reduction for the controls.

\section{Discussion}

This study has shown that the naphthalene diimide derivative 1 is a potent inhibitor of cell growth in both wild-type and imatinib-resistant GIST patient-derived cell lines (Table 2). This property is not common to all quadruplex-binding small molecules, as shown by the selectivity of the acridine compound BRACO-19, which is active in a number of laboratory cancer cell lines (as well as in vivo against tumour xenografts ${ }^{46}$ ). The fact that both compounds stabilise a range of quadruplexes in vitro (Table 1) can only be taken as correlative evidence that quadruplex targeting is involved in their mechanism of action. The exceptionally high degree of stabilisation shown by compound 1 with the c-KIT2 promoter quadruplex is in accord with the observed down-regulation of the high level of c-KIT expression in the wild-type GIST882 cell line ${ }^{13}$; the resistant line GIST48 has a lower level ${ }^{47}$ and the compound does not have a large effect on this gene. On the other hand, BCL-2 is shown here to be expressed at high levels in GIST48 cells and may play a role in chemo-resistance, in this cell line at least. BCL-2 expression is reduced to a very low level by compound 1 and we suggest that this effect is likely to be a major contributor to the overall potency of compound 1 in imatinib-resistant cells.

The concept of BCL-2 as a target in resistant GIST is in accord with several previous studies. Amplification of BCL-2 has been previously reported in GIST disease progression in the clinic $^{48}$ and BCL-2 protein expression has been found to be elevated in iminatib GIST-resistant cells. ${ }^{49}$ Also the BCL-2 protein small-molecule inhibitor ABT-737 shows activity in GIST lines. ${ }^{29}$

The observation that BCL-2 translation efficiency is reduced by compound $\mathbf{1}$ (in a reporter system) suggests that this compound is acting at the RNA (i.e. translation) level. However, in the absence of quantitative mRNA data, it is possible that compound $\mathbf{1}$ also acts at the DNA (i.e. transcriptional) level. We cannot also exclude the possibility that compound $\mathbf{1}$ has an effect on other targets and pathways in addition to the BCL-2-BAX apoptosis pathway. Indeed our recent study $^{50}$ on a trisubstituted naphthalene diimide in pancreatic cancer cell lines, using wholegenome RNA-seq methodology, revealed 47 major targets, almost all of which are quadruplexcontaining. Also we cannot at this stage exclude other intronic targets in the BCL-2 gene, which 
contain putative quadruplex sequences (see Figure S2 in the Supplementary Information), from being also targeted by compound 1 . In the context of GIST, the ability of a small molecule to down-regulate $\mathrm{BCL}-2$, a major contributor to drug-induced resistance at the gene level (thereby bypassing the mutational consequences of protein targeting) is by itself of potential therapeutic benefit in this disease. Although we cannot at present comment directly on the suitability of compound 1 as a potential therapeutic agent in GIST, several members of the broad class of highly substituted naphthalene diimide compounds have shown promising in vivo activity in models for human cancers, indicating that their pharmacological properties are compatible with acceptable norms for drug-like properties. ${ }^{39,48}$

\section{Methods}

\subsection{General}

The quadruplex-binding naphthalene diimide derivative compound $\mathbf{1}$ was synthesized and purified in-house by reverse-phase hplc following published procedures ${ }^{25}$ and was used as the $99 \%$ pure free base. It was dissolved in $100 \%$ DMSO to make a $10 \mathrm{mM}$ stock solution and aliquots were kept at $-20^{\circ} \mathrm{C}$. Stock solutions of compound 1 as free base and imatinib mesylate $\left(\right.$ Glivec $\left.^{\circledR}\right)$, purchased from ACC Corporation, were also prepared in filtered, sterilized distilled water and $100 \%$ DMSO respectively and stored as above. A $1 \mathrm{mM}$ working solution of each compound was prepared freshly on the day of the experiment in filter sterilized distilled water. The established quadruplex-binding ligand, the acridine compound BRACO-19 (synthesised and purified in-house) was also used in this study. A $1 \mathrm{mM}$ working solution of each compound was freshly prepared in filter-sterilised distilled water with $1 \% \mathrm{HCl}$, on the day of an experiment.

\subsection{Cell culture}

MCF-7 (human breast adenocarcinoma), HGC-27 (human gastric carcinoma) and HT-29 (human colorectal adenocarcinoma) cells were purchased from ATCC. MCF-7 and HT-29 cells were both maintained in DMEM. HGC-27 was maintained in MEM. Both DMEM and MEM were supplemented with $10 \%$ FBS. MCF7 cells were cultured at $37^{\circ} \mathrm{C}$ containing $5 \% \mathrm{CO}_{2}$ in Dulbecco's modified Eagle's medium (DMEM) supplemented with $10 \%$ heat-inactivated fetal calf serum (FCS) 
Three patient-derived GIST cell lines were made available by Dr JA Fletcher. GIST 882 is a primary GIST line with a gain-of-function K642E mutation in C-KIT exon 13 and is not resistant to imatinib. GIST48 is an Imatinib-resistant line from a patient with a primary homozygous V560D exon 11 missense mutation and a heterozygous secondary D820A exon 17 kinase activation loop mutation, following treatment. GIST62 is an imatinib-resistant line from a patient who did not respond to imatinib. GIST882 cells were maintained in RPMI 1640 supplemented with 15\% fetal bovine serum. GIST48 and GIST62 cells were routinely cultured and maintained in F10 media supplemented with fetal bovine serum and growth supplements.

\subsubsection{Short term cytotoxicity assay}

Cellular growth inhibition was measured using the sulforhodamine B (SRB) assay in 96 well plates as described previously. ${ }^{13,48} 50 \%$ inhibitory concentrations $\left({ }^{2} C_{50}\right)$ were determined by taking the mean absorbance at $540 \mathrm{~nm}$ for each drug concentration expressed as a percentage of the absorbance of untreated control wells. All measurements were made $>3$ times

\subsection{In vivo telomerase activity}

Telomerase activity following treatment with compound 1 was determined using the TRAPLIG modified telomere repeat amplification protocol. $1000 \mathrm{ng}$ of protein from GIST48 cells treated with compound 1 for one week was incubated with the TS forward primer (0.1 $\mu \mathrm{g}$ of 5'$d\left(\right.$ AATCCGTCGAGCAGAGTT)-3') at $30^{\circ} \mathrm{C}$ for $10 \mathrm{~min}$ to allow the initial elongation to take place. Elongated products were purified using the QIA quick nucleotide purification kit (Qiagen) according to the manufacturer's instructions and the samples were freeze-dried. Re-dissolved PCR products were subjected to amplification in master mix containing ACX reverse primer (1 $\left.\mu \mathrm{M}, \quad 5^{\prime}-\mathrm{d}\left(\mathrm{GCGCGG}[\mathrm{CTTACC}]_{3} \mathrm{CTA} \quad \mathrm{ACC}\right)-3^{\prime}\right)$, TS forward primer $\left(0.1 \mu \mathrm{g}, 5^{\prime}-\right.$ d(AATCCGTCGAGCAGAGTT)-3'), TRAP buffer, BSA $(5 \mu \mathrm{g}), 0.5 \mathrm{mM}$ dNTPs, and $2 \mathrm{U}$ of TAQ polymerase (RedHot, ABgene, Surrey, U.K.) for 35 cycles of $94^{\circ} \mathrm{C}$ for $30 \mathrm{~s}$, at $61^{\circ} \mathrm{C}$ for $1 \mathrm{~min}$, and at $72{ }^{\circ} \mathrm{C}$ for $1 \mathrm{~min}$. Samples were separated on a 12\% PAGE and visualized with SYBR green 
(Aldrich) staining. Gels were quantified using a gel scanner and gene tool software (Sygene, Cambridge, U.K.). Intensity data were obtained by scanning and integrating the total intensity of each PCR product ladder in the denaturing gels.

\subsection{Expression of c-KIT and BCL-2 proteins}

GIST48 cells were treated with compound 1 at sub-cytotoxic concentrations and samples were taken at different time points. Total protein was extracted with RIPA lysis buffer (Santa Cruz) at $4{ }^{\circ} \mathrm{C}$ and protein concentration was quantified with the BCA Protein Assay kit (Pierce). For the expression analysis of c-KIT, $500 \mu \mathrm{g}$ of total protein was immune-precipitated with c-KIT primary antibody and Protein-G beads overnight at $4{ }^{\circ} \mathrm{C}$. Following this, the immune-precipitates were washed and protein samples were boiled at $95{ }^{\circ} \mathrm{C}$ for $5 \mathrm{~min}$. Samples were separated on SDS-PAGE and probed with primary and HRP-secondary antibodies (Santa Cruz). For the expression analysis of BCL-2 and $\beta$-actin (as a control), $200 \mu \mathrm{g}$ and $50 \mu \mathrm{g}$ of total protein was separated on SDS-PAGE respectively and probed with appropriate primary and secondary antibodies (Santa Cruz). Gels were quantified using a gel scanner and gene tool software (Sygene, Cambridge, U.K.). Intensity data were obtained by scanning and integrating the total intensity of each protein band and are shown as normalised to $\beta$-actin.

\subsection{FRET studies}

FRET DNA melting assays with compound 1, imatinib and BRACO-19 were performed using a fluorescence resonance energy transfer (FRET) assay. The labelled oligonucleotides had the fluorophores FAM (6-carboxyfluorescein) as donor and fluorophore TAMRA (6carboxytetramethyl-rhodamine) attached as acceptor. All labelled sequences were purchased from Eurogentec Ltd., U.K. and used without any further purification beyond the manufacturer's hplc procedures. The sequences used were:

Human telomeric $\mathrm{G} 4$ sequence (F21T):

5'-FAM-d(GGG[TTAGGG] ${ }_{3}$ )-TAMRA-3' 
Duplex sequence:

5'-FAM-d(TATAGCTATA-[(-CH $\left.\left.\left.2-\mathrm{CH}_{2}-\mathrm{O}-\right)_{6}\right]\right)$-TATAGCTATA)-TAMRA-3'

BCL-2 5'-UTR G4 sequence

5'-FAM-r(GGGGGCCGUGGGGUGGGAGCUGGGG)-TAMRA-3'

$\mathrm{BCL}-2$ promoter $\mathrm{G} 4$ sequence

5'-FAM-d(GGGCCAGGGAGCGGGGCGGAGGGGGCGGTCGGG)-TAMRA-3'

The DNA quadruplex FRET probe sequences were diluted from stock to the correct concentration ( $400 \mathrm{nM})$ in a $50 \mathrm{mM} \mathrm{KCl}+10 \mathrm{mM}$ potassium cacodylate buffer $(\mathrm{pH} 7.4)$ and then annealed by heating to $95{ }^{\circ} \mathrm{C}$ for $10 \mathrm{~min}$, followed by cooling to RT in a heating block ( 3 - $3.5 \mathrm{hr}$ ). An identical procedure was adopted for the RNA BCL-2 sequence, which used a $50 \mathrm{mM} \mathrm{NaCl}+$ $10 \mathrm{mM}$ sodium cacodylate buffer, $\mathrm{pH}$ 7.4. Drug stock solutions (at $2 \times$ concentration) were prepared using the appropriate cacodylate buffer ( $\mathrm{pH}$ 7.4). 96-well plates (MJ Research, Waltham, MA) were prepared by aliquoting $50 \mu \mathrm{L}$ of annealed DNA into each well, followed by $50 \mu \mathrm{L}$ of the compound solutions. Measurements were made on a DNA Opticon Engine (MJ Research) with excitation at 450-495 $\mathrm{nm}$ and detection at 515-545 $\mathrm{nm}$. Fluorescence readings were taken at intervals of $0.5^{\circ} \mathrm{C}$ in the range $30-100{ }^{\circ} \mathrm{C}$, with a constant temperature being maintained for $30 \mathrm{sec}$ prior to each reading to ensure a stable value. Final analysis of the data was carried out using a script written in the Origin 7.0 (OriginLab Corp., Northampton, MA) package and its advanced curve-fitting function for derivation of $\Delta T_{m}$ values.

\subsection{Construction of plasmids}

To construct the plasmids G-wt-BCL-2 and G-mut-BCL-2 two synthetic DNA duplexes encoding a $67 \mathrm{nt}$ sequence from the 5'-UTR of the wild-type BCL-2 sequence and a mutated BCL-2 sequence were inserted into the Nhel and Not1 restriction sites of the psiCHECK-2 plasmid (Promega) upstream of the Renilla luciferase start codon. To build the DNA inserts the oligonucleotides shown below were used in a series of three PCR reactions. The reverse primer (Reverse-1) was designed to clone the entire $h R / u c$ gene from a psiCHECK-2 vector, including a Not 1 restriction enzyme site at the $3^{\prime}$ terminus, and includes an overlap on the 5 ' terminus for 
the first PCR reaction with the Forward-1 primer. The primers used to generate the G-wt-BCL-2 and G-mut-BCL-2 inserts were as follows:

Forward-1:

5'-d(CCCGTTGCTTTTCCTCTGGGAAGGATGGCTTCCAAGGTGTACGAC)-3'

Forward-2a G-wt:

5'-d(CTGGGGCGAGAGGTGCCGTTGGCCCCCGTTGCTTTTCCTCTGG)-3'

Forward-3a G-wt:

5'-d(NNNGCTAGCTGGGGGCCGTGGGGTGGGAGCTGGGGCGAGAGGTG)-3'

Forward-2b G-mut:

5'-d(GAGCTGAGGCGAGAGGTGCCGTTGGCCCCCGTTGCTTTTCCTCTGG)-3'

Forward-3b G-mut:

5'-d(NNNGCTAGCTGGAGGCCGTGAGGTGAGAGCTGAGGCGAGAGG)-3'

Reverse-1: 5'-d(NNNGCGGCCGCTTACTGCTCGTTCTTCAGCAC)-3'

The PCR reactions resulted in the following two DNA constructs where the start codon is in italics and the G-rich motif is underlined:

G-wt-BCL-2:

5'-d(CTGGGGGCCGTGGGGTGGGAGCTGGGGCGAGAGGTGCCGTTGGCCCCCG

TTGCTTTTCCTCTGGGAAGGATG)-3'

G-mut-BCL-2:

5'-d(CTGGAGGCCGTGAGGTGAGAGCTGAGGCGAGAGGTGCCGTTGGCCCCCGTT GCTTTTCCTCTGGGAAGGATG)-3'

Both the wild-type construct (G-wt-BCL-2) and the mutated construct (G-mut-BCL-2) contain the 42 bases located between the G-rich PQF sequence and the translation start site found within the wild-type $B C L-25^{\prime}$-UTR region (in addition to the $25 \mathrm{nt}$ G-rich sequence). The two inserts above were digested with Nhe1-hf and Not1-hf (NEB), treated with polynucleotide kinase and ligated into the Nhe1-hf and Not1-hf restriction enzyme sites located in the psiCHECK-2 plasmid. Competent E. coli cells $(\mathrm{DH} 5 \alpha)$ were then transformed with the ligated plasmids (by heat shock), and positive colonies checked first by restriction enzyme analysis, and 
confirmed by sequencing. Plasmids were amplified in $E$. coli liquid culture and purified on standard anion-exchange spin columns (Promega).

\subsection{In vitro dual luciferase reporter assay}

G-wt-BCL-2, G-mut-BCL-2 and unmodified psiCHECK-2 plasmids were linearized by digestion with BamHI restriction endonuclease and purified by agarose gel electrophoresis. Approximately $1 \mu \mathrm{g}$ of each linear plasmid template was then added to a $20 \mu \mathrm{L}$ in vitro transcription reaction (Ambion) to generate mRNA transcripts. mRNA transcripts were purified using centrifugal columns (Ambion), with $2 \mu \mathrm{g}$ of linear mRNA from each plasmid then used per $50 \mu \mathrm{L}$ rabbit reticulocyte lysate in vitro translation reaction (Promega). These reactions were incubated at $30 \stackrel{\circ}{\circ}$ for 90 minutes followed by assessment of luminescence activity following the manufacturer's instructions (Promega) using a luminometer.

\subsection{Transient transfection and dual luciferase reporter assay in cells}

GIST882 cells $\left(1.0 \times 10^{5}\right)$ were seeded into 96 -well plates with $100 \mu$ l/well of RPMI1640 medium plus $15 \%$ fetal calf serum and $2 \mathrm{mM}$ glutamine. Transfection was carried out in 96 -well plates using Lipofect- AMINE 2000 (Invitrogen) according to the manufacturer's instructions, using modified and unmodified psiCHECK-2 plasmids. $333 \mathrm{ng}$ of plasmid DNA in $25 \mu \mathrm{L}$ DMEM without serum, along with $0.4 \mu \mathrm{L}$ of LipofectamineTM 2000 in $25 \mu \mathrm{L}$ of DMEM were added sequentially into each well. Dilutions were incubated at room temperature for $5 \mathrm{~min}$, then mixed together gently and incubated for $20 \mathrm{~min}$. Thirty-six hours after transfection cells were re-suspended in PBS passive lysis buffer (Promega). Cells in each well were lysed with $20 \mu \mathrm{L}$ of lysis buffer. The lysates were assayed by using the Dual-Luciferase ${ }^{\circledR}$ Reporter Assay System (Promega). The average value and standard deviation of triply prepared samples was calculated using the Microsoft Excel software. The firefly and Renilla luciferase activities were measured using the Dual-luciferase Reporter Assay kit (Promega) according to the manufacturer's instructions with a luminometer 


\subsection{Transient transfection with compound 1}

Compound 1 was used to quantify, in a concentration dependent manner, any possible stabilization in vitro of the 5'UTR BCL-2 putative quadruplex forming sequence. The ligand, dissolved in $100 \%$ DMSO, was added in vitro in concentrations ranging from 0.01 to $1 \mu \mathrm{M} /$ well. Each sample of ligand addition to a cell sample was prepared in triplicate. The concentrations and the addition of compound 1 for plasmid psiCHECK-2, G-wt-BCL-2 and G-mut-BCL-2 were the same for the transfection.

\section{Acknowledgements}

We are grateful to Cancer Research UK for support of the earlier stages of this project, to Dr Xiong Wei Li for work on the plasmids used in this study, and to Dr Jonathan Fletcher, Brigham and Women's Hospital Harvard Medical School, for the generous provision of GIST cell lines and much useful discussion.

\section{References:}

1. Yarden Y, Kuang WJ, Yang-Feng T, Coussens L, Munemitsu S, Dull TJ, Chen E, Schlessinger J, Francke U, Ullrich A. EMBO J. 1987;6:3341-3351.

2. Corless CL, Barnett CM, Heinrich MC. Nat Rev Cancer. 2011;11:865-878.

3. Ashman LK, Griffith R. Expert Opin Investig Drugs. 2013;22:103-115.

4. Fletcher JA, Rubin BP. Curr Opin Genet Dev. 2007;7:3-7.

5. Heinrich MC, Blanke CD, Druker BJ, Corless CL. J Clin Oncol. 2002;20:1692-1703.

6. Kang W, Zhu C, Yu J, Ye X, Ma Z. Front Biosci (Landmark Ed). 2015;20:919-926.

7. Jakhetiya A, Garg PK, Prakash G, Sharma J, Pandey R, Pandey D. World J Gastrointest Surg. 2016;8:345-352. 
8. Szucs Z, Thway K, Fisher C, Bulusu R, Constantinidou A, Benson C, van der Graaf WT, Jones RL. Future Oncol. 2017;13:93-107.

9. Hopkins TG, Marples M, Stark D. Eur J Surg Oncol. 2008;34:844-850.

10. Mulet-Margalef N, Garcia-Del-Muro X. Onco Targets Ther. 2016;9:7573-7582.

11. Overton LC, Heinrich MC. Expert Opin Pharmacother. 2014;15:549-558.

12. Schvartsman G, Wagner MJ, Amini B, Zobniw CM, Trinh VA, Barbo AG, Lin HY, Wang WL, Conley AP, Ravi V, Araujo DM, Zarzour MA, Benjamin RS, Patel S, Somaiah N. Sci Rep. 2017;7:9519.

13. Gunaratnam M, Beltran M, Galesa K, Haider SM, Reszka AP, Cuenca F, Fletcher JA, Neidle S. J Med Chem. 2009;52:3774-3783.

14. Rankin S, Reszka AP, Huppert J, Zloh M, Parkinson GN, Todd AK, Ladame S, Balasubramanian S, Neidle S. J Amer Chem Soc. 2005;127:10584-10589.

15. Fernando H, Reszka AP, Huppert J, Ladame S, Rankin S, Venkitaraman AR, Neidle S, Balasubramanian S. Biochemistry 2006;45:7854-7860.

16. Phan AT, Kuryavyi V, Burge S, Neidle S, Patel DJ. J Amer Chem Soc. 2007;129:4386-4392.

17. Hsu ST, Varnai P, Bugaut A, Reszka AP, Neidle S, Balasubramanian S. J Amer Chem Soc. 2009;131:13399-13409.

18. Wei D, Husby J, Neidle S. Nucleic Acids Res. 2015;43:629-644.

19. Wei D, Parkinson GN, Reszka AP, Neidle S. Nucleic Acids Res. 2012;40:4691-4700.

20. Kuryavyi V, Phan AT, Patel DJ. Nucleic Acids Res. 2010;38:6757-6773.

21. Burge S, Parkinson GN, Hazel P, Todd AK, Neidle S. Nucleic Acids Res. 2006;34:54025415.

22. Jantos K, Rodriguez R, Ladame S, Shirude PS, Balasubramanian S. J Amer Chem Soc. 2006;128:13662-13663.

23. Bejugam M, Sewitz S, Shirude PS, Rodriguez R, Shahid R, Balasubramanian S. J Amer Chem Soc. 2007;129:12926-12927.

24. Bejugam M, Gunaratnam M, Müller S, Sanders DA, Sewitz S, Fletcher JA, Neidle S, Balasubramanian S. ACS Med Chem Lett. 2010;1:306-310. 
25. Cuenca F, Greciano O, Gunaratnam M, Haider S, Munnur D, Nanjunda R, Wilson WD, Neidle S. Bioorg Med Chem Lett. 2008;18:1668-1673.

26. Read M, Harrison RJ, Romagnoli B, Tanious FA, Gowan SH, Reszka AP, Wilson WD, Kelland LR, Neidle S. Proc Natl Acad Sci USA. 2001;98:4844-4849.

27. Izbicka E, Wheelhouse RT, Raymond E, Davidson KK, Lawrence RA, Sun D, Windle BE, Hurley LH, Von Hoff DD. Cancer Res. 1999;59:639-644.

28. Steinert DM, Oyarzo M, Wang $X$, Choi $H$, Thall PF, Medeiros $\amalg$, Raymond AK, Benjamin RS, Zhang W, Trent JC. Cancer. 2006;106:1617-1623.

29. Reynoso D, Nolden LK, Yang D, Dumont SN, Conley AP, Dumont AG, Zhou K, Duensing A, Trent JC. Mol Oncol. 2011;5:93-104.

30. Garner TP, Lopez A, Reyna DE, Spitz AZ, Gavathiotis E. Curr Opin Chem Biol. 2017;39:133-142.

31. Tsujimoto Y, Cossman J, Jaffe E, Croce CM. Science. 1985;228:1440-1443.

32. Dai J, Dexheimer TS, Chen D, Carver M, Ambrus A, Jones RA, Yang D. J Amer Chem Soc. 2006;128:1096-1098.

33. Dai J, Chen D, Jones RA, Hurley LH, Yang D. Nucleic Acids Res. 2006;34:5133-5144.

34. Agrawal P, Lin C, Mathad RI, Carver M, Yang D. J Amer Chem Soc. 2014;136:1750-1753.

35. Onel B, Carver M, Wu G, Timonina D, Kalarn S, Larriva M, Yang D. J Amer Chem Soc. 2016;138:2563-2570.

36. Shahid R, Bugaut A, Balasubramanian S. Biochemistry. 2010;49:8300-8306.

37. Bugaut A, Balasubramanian S. Nucleic Acids Res. 2012;40:4727-4241.

38. Wang XD, Ou TM, Lu YJ, Li Z, Xu Z, Xi C, Tan JH, Huang SL, An LK, Li D, Gu LQ, Huang ZS. J Med Chem. 2010;53:4390-4398.

39. Ohnmacht SA, Marchetti C, Gunaratnam M, Besser RJ, Haider SM, Di Vita G, Lowe HL, Mellinas-Gomez M, Diocou S, Robson M, Šponer J, Islam B, Pedley RB, Hartley JA, Neidle S. Sci Rep. 2015;5:11385.

40. Feng Y, Yang D, Chen H, Cheng W, Wang L, Sun H, Tang Y. Bioorg Med Chem Lett. 2016;26:1660-1663. 
41. Micheli E, Altieri A, Cianni L, Cingolani C, lachettini S, Bianco A, Leonetti C, Cacchione S, Biroccio A, Franceschin M, Rizzo A. Biochimie. 2016;125:223-231.

42. Amato J, Pagano A, Capasso D, Di Gaetano S, Giustiniano M, Novellino E, Randazzo A, Pagano B. ChemMedChem. 2018;13:406-410.

43. Bugaut A, Rodriguez R, Kumari S, Hsu ST, Balasubramanian S. Org Biomol Chem. 2010;8:2771-2776.

44. Miglietta G, Cogoi S, Marinello J, Capranico G, Tikhomirov AS, Shchekotikhin A, Xodo LE. J Med Chem. 2017;60:9448-9461.

45. Simone R, Balendra R, Moens TG, Preza E, Wilson KM, Heslegrave A, Woodling NS, Niccoli T, Gilbert-Jaramillo J, Abdelkarim S, Clayton EL, Clarke M, Konrad MT, Nicoll AJ, Mitchell JS, Calvo A, Chio A, Houlden H, Polke JM, Ismail MA, Stephens CE, Vo T, Farahat AA, Wilson WD, Boykin DW, Zetterberg $H$, Partridge L, Wray S, Parkinson $G$, Neidle $S$, Patani R, Fratta P, Isaacs AM. EMBO Mol Med. 2018;10:22-31.

46. Burger AM, Dai F, Schultes CM, Reszka AP, Moore MJ, Double JA, Neidle S. Cancer Res. 2005;65:1489-1496.

47. Bauer S, Duensing A, Demetri GD, Fletcher JA. Oncogene. 2007;26:7560-7568.

48. Yang D, Ylipaa A, Yang J, Hunt K, Pollock R, Trent J, Yli-Harja O, Shmulevich I, Nykter M, Zhang W. Technol Cancer Res Treat. 2010;9:171-178.

49. Steinert DM, Oyarzo M, Wang X, Choi H, Thall PF, Medeiros $L$, Raymond AK, Benjamin RS, Zhang W, Trent JC. Cancer. 2006;106:1617-1623.

50. Marchetti C, Zyner KG, Ohnmacht SA, Robson M, Haider SM, Morton JP, Marsico G, Vo T, Laughlin-Toth S, Ahmed AA, Di Vita G, Pazitna I, Gunaratnam M, Besser RJ, Andrade ACG, Diocou S, Pike JA, Tannahill D, Pedley RB, Evans TRJ, Wilson WD, Balasubramanian S, Neidle S. J Med Chem. 2018;61:2500-2517. 


\section{Figure legends}

Figure 1. The structure of compound 1 (N,N'-Bis(2-(pyrrolidin-1-yl)ethylamino)-2,6-bis(2(pyrrolidin-1-yl)ethylamino)-1,4,5,8-naphthalenetetracarboxylic acid diimide)

Figure 2a. Polyacrylamide gels showing telomerase activity in cells treated with compound $\mathbf{1}$ for one week. The LHS shows GIST882 treated cells, with lane 1 showing the vehicle control (VC), lane 2; $0.5 \mu \mathrm{M}$ of compound 1, lane 3 shows the negative control. The RHS shows GIST48 treated cells, with lane 1 showing the vehicle control (VC), and lanes 2-6 showing the results of treatment with increasing concentrations of compound; lane 7 shows the negative control.

Figure $\mathbf{2 b}$ b. Immunoblotting of total c-KIT protein in GIST48 cells. The upper panel shows total cKIT after treatment with compound 1 for 24 hrs and the lower panel shows c-KIT after 1 week treatment. In each case the left-hand blot shows the $\beta$-actin control.

Figure 2c. Quantitation of these changes in c-KIT expression, normalised against untreated control $\beta$-actin expression.

Figure 3a. Immunoblotting of total BCL-2 protein in GIST48 and GIST882 cells.

Figure 3b. Immunoblotting of total BCL-2 protein in GIST48 cells. The top panel shows total BCL2 after treatment with compound 1 for $24 \mathrm{hrs}$, the central panel for $72 \mathrm{hrs}$ and the lower panel shows BCL-2 after one week of treatment. In each case the right-hand blot shows the $\beta$-actin control.

Figure 3c. Quantification of the total BCL-2 protein in GIST48 cells, shown as a dose-response plot following compound 1 treatment at a $0.3 \mu \mathrm{M}$ concentration.

Figure 4a. Schematic showing the three dual-luciferase plasmid constructs used here, with respectively, null, mutated (G-mut-BCL-2) and wild-type (G-wt-BCL-2) 5'-UTR quadruplex sequences inserted upstream of the Renilla luciferase gene. White arrows indicate viral promoter sites.

Figure $\mathbf{4 b}$. Plot showing changes in protein expression at three different concentrations of compound 1, as measured by the ratio of Renilla/firefly luminescence, following plasmid transfection into GIST882 cells. Standard deviations following >3 determinations are shown as error bars. 